\title{
Ethnic Group Labelling and the Reporting of National Educational Outcomes in New Zealand
}

\author{
John Boereboom ${ }^{1}$
}

Received: 15 December 2016/ Accepted: 14 July 2017/Published online: 19 July 2017

(C) The Author(s) 2017. This article is an open access publication

\begin{abstract}
The New Zealand education system is culturally diverse and is guided by the principles of the Treaty of Waitangi to produce equitable outcomes for Māori students. The reporting of national educational outcomes is broken down by ethnicity to monitor educational performance of different ethnic groups and to identify ethnic disparities. The Ministry of Education and the New Zealand Qualification Authority use a system of ethnic priority ranking to expedite the statistical analysis of educational outcomes for students who identify themselves as belonging to more than one ethnic group. This approach may inadvertently distort reported ethnic disparities in key outcomes of our education system. The study investigates the impact of the method of ethnic labelling on reported national outcomes of the education system and recommends an alternative weighted ethnicity approach. Questions are raised about the appropriateness of the current ethnic classifications.
\end{abstract}

Keywords Ethnicity labelling $\cdot$ National assessment $\cdot$ NCEA reporting $\cdot$ National outcomes

\section{Introduction}

New Zealand society is a melting pot of different races, ethnicities, nationalities, languages and cultures. Projections indicate that New Zealand will be even more culturally and ethnically diverse in the future. The 2013 census data shows that the ethnicity of the New Zealand population aged under 18 years is more diverse $(72 \%$ European, 24\% Māori, 12\% Pacific and 10\% Asian) than the population aged

John Boereboom

John.boereboom@canterbury.ac.nz

1 Centre for Evaluation and Monitoring, University of Canterbury,

Private Bag 4800, Christchurch 8140, New Zealand 
65 years or older (91\% European, 5\% Māori, 4\% Asian and 2\% Pacific) (New Zealand Statistics 2013). While this high level classification of New Zealand's ethnic composition paints a neat canvas of well-defined ethnic groups, the reality is that an increasing number of New Zealanders view themselves as multi-ethnic. The ethnic landscape is even more diverse when finer grained ethnic classification schemes are used.

Historically the construct of ethnicity has a strong biological and racial origin and was viewed as a variable which could be precisely measured and remained unchanged from birth to death (Khawaja et al. 2000).

This approach is currently used in the USA where educational statistics are broken down by race including "American Indian or Alaska Native, Asian, Black or African American, Native Hawaiian or Other Pacific Islander and White" (Aud et al. 2010, p. 1). In Australia, ancestry is used to define ethnic groups and government reports include outcomes for Aboriginal and Torres Strait Islanders (Australian Bureau of Statistics 2011).

In New Zealand there has been a paradigm shift from a racial and biological focus to one of socio-cultural self-identification. The evidence for this can be seen in the evolution of census questions related to race and ethnicity. In the 1916 census non-European respondents were asked to identify themselves by race. Māori respondents were asked to identify whether they were 'Maori' or 'Maori half-caste'. By 1976 the census form had been altered to give categories for 'full NZ Maori' and fractions of Māori ethnicity such as '1/8 Maori'. The 1986 Population Census was the first census that enabled people to respond to the ethnicity question based on their self-reported cultural affiliation. In the 2006 census respondents could tick as many boxes as needed to represent their ethnicity (Taonui 2011).

The current view of ethnicity as a fluid social construct has evolved over time and includes the idea that an individual can legitimately self-identify with only some, or even none, of their biological lineage. This definition of ethnicity reflects the global principles of the Declaration on the Rights of Indigenous People to selfdetermination, to name themselves and to express their cultural identity (United Nations 2007). New Zealand's national identity reflects principles of egalitarianism and classlessness (Murphy 2003). The evolution in the definition of ethnicity is largely due to the effects of globalisation, immigration, intermarriage and a revitalised interest in acknowledging and taking pride in our multi-ethnic backgrounds.

The New Zealand Statistical Standard for Ethnicity (Statistics New Zealand 2016 , p. 1) defines "ethnicity as the ethnic group that people identify with or feel they belong to." An ethnic group is "made up of people who have some or all of the following characteristics:

- a common proper name

- one or more elements of common culture which need not be specified, but may include religion, customs, or language

- unique community of interests, feelings and actions

- a shared sense of common origins or ancestry, and

- a common geographic origin." 
New Zealand's rapidly growing ethnic diversity presents specific challenges to report on social data in a way that adequately meets end users' needs and which is collected in a way that is culturally sensitive to all ethnic groups.

To ensure that the reporting is relevant and useful in the current socio-political context the processes need to be critically reflected on to ensure that they continue to meet the needs of society in general and end users in particular. There are two main aspects to be considered. These include the usefulness of the current labels used to describe the ethnic groups and the statistical approaches used to analyse the data for multi-ethnic respondents.

The present system of Level 1 ethnicity classification includes the following ethnic groups; Māori, Pasifika, Asian, MELAA, Other and New Zealand European/ Pākehā. These arbitrarily defined ethnic labels do not appear adequate to describe New Zealand's complex cultural landscape. The differences within some of these ethnic groupings may in some instances be larger than the differences between the groups. Cohen (1978, p. 383) cautioned that "the identification of ethnic groups in the usage of social scientists often reflected inaccurate labels that are often arbitrarily, or even worse inaccurately, imposed".

The MELAA category for instance aggregates people from the Middle East, Africa and Latin America. This category does not meet the Statistics New Zealand definition of an ethnic group. This group does not share a common geographic origin or homogeneity of religion, customs or language. It is difficult to see how the summary statistics for such a diverse group can be useful to inform social policy decision making. The category could be abolished and included in the "other" category. The more fine-grained Level 2 classification could subsequently be used if analysis of data for a specific ethnic group in this category is required. The educational success and needs of Somali refugees is an example of the use of this data.

The label 'New Zealand European/Pākehā' describes the dominant ethnic group in New Zealand (Statistics New Zealand 2004, p. 15). This label is seen by many as inappropriate because many people have lived in New Zealand for several generations and they consider that their roots are in New Zealand not Europe (Statistics New Zealand 2009). It is time for New Zealand to come of age by including the category 'New Zealander' for respondents who identify with our unique national identity. This label is independent of the geographical roots of our ancestors and is an expression of identity by people who have a generational attachment to New Zealand. Support for this view is found in a comment reported in Cormack and Robson (2010, p. 7) "Many of us however consider that we, and our families, have been in New Zealand for long enough that we should be able to claim who we are, regardless of where our ancestors may have come from many centuries ago or what the colour of our skin or shape of our face might indicate." A relabelling of this category would also remove confusion with European immigrants to New Zealand who are included in the "other" category.

While the definition of ethnicity is a fluid social construct, statistical analysis is an algorithmic mathematical process which requires narrow and precise definition of variables. To report on census data and facilitate statistical analysis, Statistics New Zealand developed a system of ethnic priority ranking (Khawaja et al. 2000). 
This system involves assigning multi-ethnic students to a single prioritised ethnic group for the purpose of statistical analysis. This system is used across all government sectors and has pedagogical implications for the reporting of national educational outcomes.

The New Zealand education system is a microcosm of New Zealand society. This is reflected in the cultural and ethnic diversity of the student and teacher populations and composition of Boards of Trustees. Bishop et al. (2009, p. 1) highlighted that "The major challenges facing education in New Zealand today are the continuing social, economic and political disparities within our nation" These disparities are reflected in the national statistics on participation and achievement in the education system.

To optimise the performance of the education system, accurate reporting of useful and high-quality data is necessary to identify educational policy priorities and to provide consistent, reliable, complete, and accurate information on national educational outcomes. The reporting on national educational outcomes is broken down by ethnicity and enables the identification of disparity and inequity in national educational outcomes.

The reporting informs the setting of national and school targets to reduce ethnic disparities. The Māori Education Strategy: Ka Hikitia: Accelerating Success 2013-2017 "aims to change how the education system performs so that all Māori students gain the skills, qualifications and knowledge they need to enjoy and achieve education success as Māori" (MoE 2016a, p. 13). The progress made in the national key indicators is monitored by, Ngā Haeata Mātauranga which assesses Māori education. Similar aspirational goals are set by the Pasifika Education Plan 2013-2017 which is "aimed at raising Pasifika learners' participation, engagement and achievement from early learning through to tertiary education." (MoE 2016b, p. 1).

The analysis of ethnic group differences in national educational outcomes and Māori and Pasifika achievement in particular, is a routine component of the reporting of the annual national achievement data for The National Certificate of educational Achievement (NCEA). It is of interest to students, parents, schools, tertiary institutions and government organisations like the MoE, NZQA and the Education Review Office (ERO).

The Statistical Standard for Ethnicity (Statistics New Zealand 2016, p. 1) specifies that "When collecting ethnicity information, people need to be able to state their specific ethnic groups without being forced to identify themselves in a more general category." The Ministry of Education (MoE) and the New Zealand Qualifications Authority (NZQA) collect ethnicity data and enable students to nominate up to three ethnic groups with which they identify. The NCEA (NZQA 2016 , p. 1) candidate registration form asks students to "Tick the box(es) next to the ethnic group(s) you feel you belong (Maximum of 3 boxes)." This method allows for the nomination of multiple ethnicities but does not facilitate the identification of the ethnic group towhich students most strongly identify. This poses challenges for reporting and interpretation of key national educational outcomes for different ethnic groups and raises the issue of how to statistically analyse and report on 
national educational outcomes when students identify themselves as belonging to more than one ethnic group.

To facilitate the ethnicity breakdown in the analysis and reporting of national assessment data, NZQA uses the system of ethnic priority ranking developed by Statistics New Zealand to assign a single priorities ethnic group to candidates who identify with more than one ethnic group. Table 1 shows the rank order in which ethnicity classifications are prioritised.

The following example illustrates how the system of priority ranking works in practice. On the NCEA registration form a candidate may tick the Māori, Pasifika and European/Pākehā boxes to describe their ethnicity. The student may identify themselves most strongly as Pasifika but according to the priority ranking they would only be included in the Māori statistical category.

The construct of ethnicity is highly personal and individualised. In New Zealand's socio-political context it seems ethically inappropriate to override students' personal identification of the ethnic group they most strongly identify with and relate to, with a mandatory algorithmic system of ethnic priority ranking.

The practice of ethnic priority ranking and its social consequences has remained relatively unexamined and unchallenged because it has occurred quietly in the background. The practice may be appropriate in some government sectors like the health sector where some indication of genetic lineage may be useful for the purpose of ethnic patterns in certain diseases. However in the education sector where ethnicity is a purely social construct, its use is controversial when interpreted in the context of the Treaty of Waitangi and the principles of Tino Rangatiratanga. Khawaja et al. (2000) make the observation that for many Māori "the idea of being asked to identify with only the Māori ethnic group could give offence to their nonMāori ancestors, just as any subsequent assignment of people to only one of the groups they have specified would be disrespectful to that individual."

An unintended potential effect of the system of ethnic priority ranking is that it could inadvertently distort and bias the reporting of trends in the education system by ameliorating or exacerbating ethnic differences in the reporting on key outcomes.

Key educational outcomes that are statistically broken down by ethnicity include school attendance, stand downs, the literacy and numeracy component of NCEA,

Table 1 Priority rankings for prioritising ethnic classification of NCEA candidates

\begin{tabular}{ll}
\hline Ethnic group & $\begin{array}{l}\text { Ranking for } \\
\text { prioritised reporting }\end{array}$ \\
\hline Māori & 1 st \\
Pasifika & 2 nd \\
Asian & 3 rd \\
MELAA (Middle Eastern/Latin American/ & 4 th \\
African)* & \\
Other & 5 th \\
NZ European/Pākehā & 6 th \\
\hline
\end{tabular}


the endorsement of NCEA certificates and University Entrance. The MoE uses different approaches for statistically analysing ethnic data and reporting on the differences between ethnic groups for different contexts.

For example the current system of ethnic priority ranking is used by the MoE to report on the national stand down statistics for different ethnic groups. The Ministry of Education (2016c) reports that "schools continue to stand-down, suspend, and exclude more Māori students than any other ethnic group."

Figure 1 (MoE 2016c) clearly shows that under the current system of reporting, Maori have the highest stand down rates followed by the Pasifika and Asian ethnic groups. The ethnic group with the least number of stand downs per 1000 students is the European/Pakeha group. Figure 1 shows that "Asian and European/Pākehā had the biggest drops in stand-down rates between 2014 and 2015. The Asian agestandardised rate dropped 6.6\%, and the European/Pākehā rate dropped 2.0\%" (Ministry of Education 2016c).

These trends are not surprising given the fact that all multi-ethnic students who nominate Māori as one of the ethnic groups they identify with are automatically included in the Māori statistics and that the statistics for European students exclude all multi-ethnic students. This kind of reporting accentuates trends and reinforces stereotypes.

The statistics would paint a different picture if students were included in the category they self-identified with or a proportional ethnicity approach was used. The number of Māori and Pasifika stand downs would be lower than the current reported levels.

Another key indicator of the national educational performance of the education system is school attendance. Figure 2 shows that the percentages of Māori and Pasifika students attending school regularly are significantly lower than that of European/Pākehā and Asian students.

In the processing of the national school attendance data the MoE uses a different approach to analysing the data called "total response ethnicity" where "students who identified in more than one ethnic group have been counted in each group but only once in the Total" (MoE 2016d). This approach is problematic since including

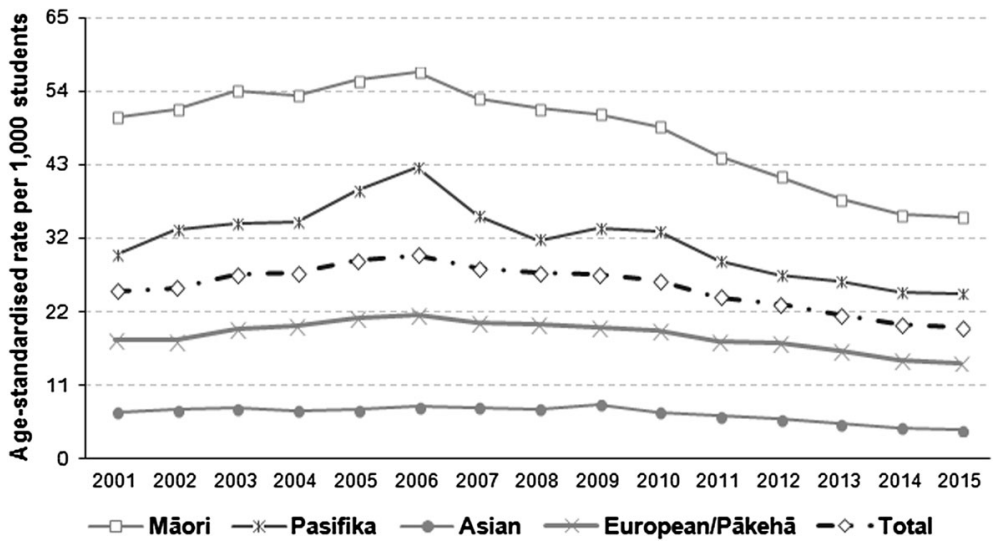

Fig. 1 Age-standardised stand-down rates by ethnic group (2001-2015) (Ministry of Education 2016c) 


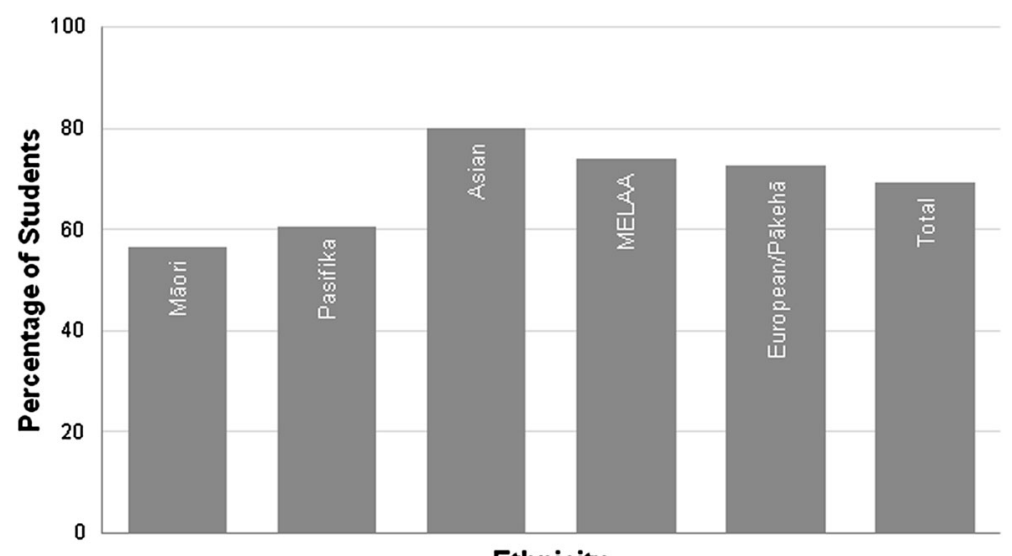

Ethnicity

Fig. 2 Students attending school regularly, by ethnicity, term 2, 2015 (MoE 2016d)

multi-ethnic students in more than one ethnic group increases the denominator on which percentages are calculated and has the effect of reducing the percentage values resulting in an under reporting of trends when compared with the Total cohort. It means that the combined total of the number of students in all ethnic groups exceeds the total number of students analysed. This data could be more appropriately reported on by using a proportional representation approach to analysing the data.

A Ministry of Education (2010) 'Māori fact sheet' highlights some key statistics on Māori senior secondary students' achievement in the National Certificate of Educational Achievement (NCEA). This fact sheet was last updated in 2010 and is based on the 2009 NCEA results. This report illustrates the deficit approach to ethnic disparity reporting. Some key findings include:

- "Non-Māori students have a higher attainment rate in NCEA qualifications

- $48 \%$ of year 11 Māori students gained an NCEA qualification. This compares to $69 \%$ of non-Māori

- Male Māori students continue to be the least likely group to gain a qualification

- $66 \%$ of Māori students achieved both the literacy and numeracy requirements for NCEA Level 1 by the end of Year 11. This compares to 79\% of non-Māori students.

- $29 \%$ of year 13 Māori students and 54\% of year 13 non-Māori students met the requirements for University Entrance (UE)."

This kind of summary reporting paints a sobering picture of Māori student achievement. When reporting on ethnic differences this way, there is a danger that these differences are attributed to the ethnicity of the students rather than broader social and economic factors. This can inadvertently contribute to ethnic stereotyping. Tawhai (2015) warned that "the decades that we have had of Māori students' underachievement points directly to the fact that teachers in New Zealand still have really racist stereotypes as to the level to which Māori students can achieve" (as 
cited in Nichol 2015, p. 1). To avoid reinforcing ethnic stereotypes, great care needs to be taken in the way statistics on ethnic differences in national educational outcomes are reported.

While the statistical procedures used in the analyses of national stand downs and school attendance are no doubt robust and well intentioned, one cannot help but ask whether these so called "Māori facts" would look any different if an alternative approach was used to identify and report on ethnicity?

The current practice of the reporting of the educational performance of different ethnic groups in New Zealand is based on the system of ethnic priority ranking and has the potential to either mask or accentuate ethnic differentials and can inadvertently contribute to reinforce ethnic stereotyping. Alternative ethnic analyses are used to report on different outcomes. Clearly a more consistent approach is needed which safeguards the cultural validity of statistical reporting of ethnicity comparisons.

There are other mechanisms for reporting on ethnic data. One such method for analysing ethnic comparisons in achievement data is the self-reporting of ethnicity. Kukutai (2004) explains that under this method, students who identify with more than one ethnic group are able to indicate which group they most strongly identify with rather than have that decision made for them by an arbitrary and impersonal priority ranking system. This approach cannot be used with the current method of data collection for NCEA. The enrolment form does not ask students with which ethnic group they most strongly identify. A pitfall in this approach is that it seems unfair to ask students to rank the different ethnicities in their backgrounds. It is analogous to asking a child which parent they love the most.

Another method is to only include students who have nominated a single ethnicity in the statistics for that ethnic group and create a new category for students who have nominated multiple ethnicities. This follows the earlier quoted example of the US where a 'two or more race' category exists. This approach is statistically expedient but is inappropriate for the New Zealand context because it does not accurately report on multi-ethnic students.

Arguably the most culturally inclusive and representative method is to use a weighted ethnicity or proportional representation approach which recognises all of the nominated ethnicities in students' backgrounds by including them proportionally in the reporting on national educational outcomes. The current research reflects on the feasibility of using this method and investigates its impact on reported outcomes.

\section{Method}

This study compares the status quo of ethnic rank priority labelling with a weighted ethnicity proportional representation approach for analysing national ethnic group achievement data for NCEA. The purpose of this comparison is to analyse the statistics using different lenses to explore the impact of ethnic labelling on the reporting of key outcomes and to investigate the feasibility of the alternative weighted ethnicity method. 
The statistical comparison of the ranked ethnicity method with the weighted ethnicity method of reporting was broken into two parts.

Part 1 involved the comparison of the two methods of reporting on the whole cohort of 2015 NCEA Level 1 candidates. The purpose of this analysis was to investigate the feasibility of a change of reporting by considering the impact on the national summary data. This is important since time series data and national target setting depend on the longitudinal comparability of data.

Part 2 involved the comparison of the two methods of reporting on a subset of the national cohort of 2015 students who attained credits for NCEA Level 1 in 2015. The subset consisted of all the students who self-identified as belonging to more than one ethnic group. This sample was selected to focus on the impact of labelling on the reporting of achievement of multi-ethnic students who are directly affected by the process of priority ranking.

For each part of the analysis the following global summary indicators in the national achievement data for NCEA Level 1 were used:

- The mean number of Achievement Standards passed with A or higher.

- The mean of the total number of credits registered for NCEA Level 1.

- The percentage of students gaining A, M and E grades.

For each of the two samples, two methods for analysing the data were used. The first method of analysis reports on the ethnic breakdown of the success indicators for NCEA using the current system of ethnic priority ranking used by NZQA.

The second method of analysis reports on the ethnic breakdown of the success indicators for NCEA using ethnicity weighting. Students who identify as dual ethnicity are weighted with 0.5 weighting for each ethnicity. Students who nominate three ethnicities are weighted 0.33 for each ethnic group. The student in the earlier quoted example who identified as belonging to the Māori, Pasifika and NZ European ethnic groups is represented in each of these ethnic groups with a 0.33 weighting.

To illustrate how this process was used to analyse the national statistics, Table 2 shows a subset of fictitious students who have ticked one or more than one ethnicity category on the NCEA registration form. The numbers of credits registered were randomly assigned for illustrative purposes.

Table 3 compares how these students are labelled using the two methods for ethnic classification.

Table 2 A fictitious subset of NCEA results for 5 multi-ethnic students

\begin{tabular}{lllll}
\hline Student & Ethnicity 1 & Ethnicity 2 & Ethnicity 3 & Total number of credits \\
\hline 1 & Māori & European/Pākehā & & 70 \\
2 & Pasifika & Maori & & 80 \\
3 & European/Pākehā & Pasifika & & 60 \\
4 & Asian & Māori & European/Pākehā & 100 \\
5 & Māori & European & Pasifika & 120 \\
\hline
\end{tabular}


Table 3 Allocation of ethnicities for reporting

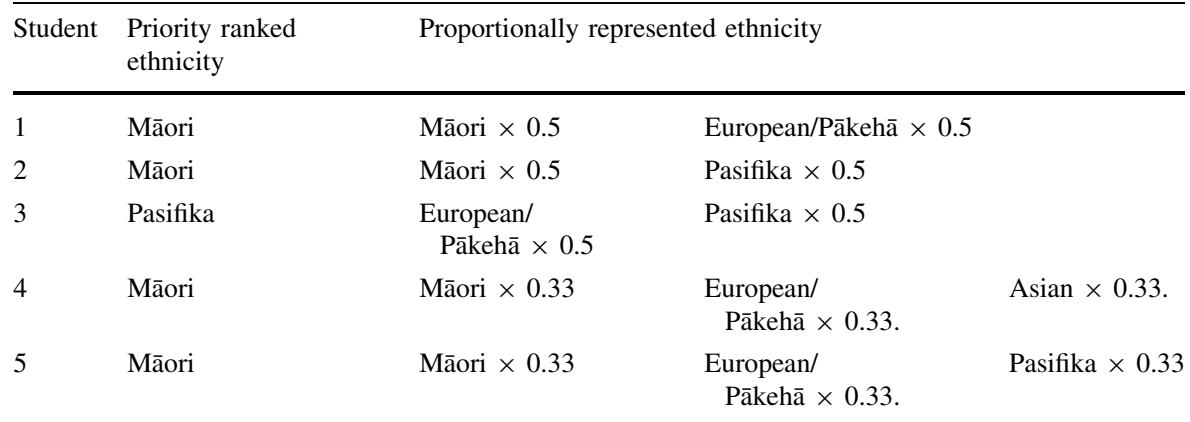

Table 4 shows a comparison of the mean number of credits achieved by each ethnic group using the ranked priority method and the weighted mean method.

The formula for calculating the mean number of credits per student for each ethnic category is

$$
\text { Mean number of credits per students }=\frac{\sum(\text { Weighting } \times \text { No of credits })}{\sum \text { Weightings for each ethnic group }}
$$

To illustrate, the European/Pākehā mean number of credits per student using the weighted mean method

$$
=\frac{(70 \times 0.5 \times 60 \times 0.5 \times 120 \times 0.33)}{05+05+0.33}=79
$$

The formula used for calculating the weighted standard deviations is

$$
S D_{\text {weighted }}=\sqrt{\frac{\sum_{i=1}^{N} w_{i}\left(x_{i}-\bar{x}_{w}\right)^{2}}{\frac{\left(N^{\prime}-1\right) \sum_{i=1}^{N} w_{i}}{N^{\prime}}}}
$$

where $w_{i}$ is the weight for the student ethnicity, $\mathrm{N}^{\prime}$ is the number of weights, and $x_{w}$ is the weighted mean.

Table 4 Mean number of credits achieved broken down by ethnic group

\begin{tabular}{lll}
\hline Ethnicity & \multicolumn{2}{l}{ Mean no of credits } \\
\cline { 2 - 3 } & Priority ranking method & Weighted ethnicity method \\
\hline Māori & 93 & 89 \\
Pasifika & 60 & 86 \\
Asian & Not reported & 101 \\
European/Pākehā & Not reported & 79 \\
\hline
\end{tabular}


The weighted ethnicity approach was applied to the national data set of results for NCEA level 1 in 2015 to investigate the feasibility and impact of applying this alternative method to the reporting of national outcome data.

Independent 2 sample t-tests were used to investigate the statistical significance of differences between the two forms of reporting using a $95 \%$ confidence interval.

\section{Results}

Table 5 shows the total number of students registered for NCEA Level 1 in 2015 and the percentages who nominated themselves as identifying with one, dual or multiple ethnic groups.

\section{Part 1: Analysis of NCEA Level 1 Results for the 2015 National Cohort}

Tables 6 and 7 show the ethnicity breakdown of the global success indicators for NCEA Level 1 for the complete 2015 national cohort.

Table 6 reports the data using the current ethnic priority ranking approach used by NZQA.

Table 7 reports on the national achievement data using the ethnicity weighting approach.

A comparison of the two methods of analysing the national achievement data shows that there are no significant differences in the reported outcome indicators. This suggests that the weighted mean method can be adopted without affecting longitudinal monitoring of time series data and national target setting.

There appears to be a slight reduction in the mean number of credits attained in NCEA Level 1 by Maori students (76-74) and a slight increase in the in the mean number of credits attained in NCEA Level 1 by Pasifika students (83-86). Since multiethnic students make up only $13.1 \%$ of the national cohort the extent of this effect could be diluted. To investigate the impact of the two types of reporting in greater detail the analyses were repeated with a focus on the subset of multi-ethnic students.

\section{Part 2: Analysis of NCEA Level 1 Results for the 2015 Subset of Multi- ethnic Students}

Table 8 shows the ethnic group achievement in NCEA using the priority ranked method for the subset of multi-ethnic students in the 2015 national Level 1 NCEA cohort.

Table 5 Ethnic groups nominated by the 2015 cohort of NCEA Level 1 candidates

\begin{tabular}{ll}
\hline Number of ethnic groups identified with & Percentage of candidates $(\mathrm{N}=58,068)$ \\
\hline 1 & 86.9 \\
2 & 11.7 \\
3 & 1.4 \\
\hline
\end{tabular}


Table 62015 NCEA Level 1 success indicators broken down by ethnic group using the priority ranking approach

\begin{tabular}{lllllll}
\hline Ethnic group & $\begin{array}{l}\text { Mean number of } \\
\text { credits attained in } \\
\text { NCEA Level 1 }\end{array}$ & $\begin{array}{l}\text { Mean number } \\
\text { of AS passed } \\
\text { with A or higher }\end{array}$ & $\begin{array}{l}\text { \% of AS } \\
\text { attained } \\
\text { with N }\end{array}$ & $\begin{array}{l}\% \text { of AS } \\
\text { attained } \\
\text { with A }\end{array}$ & $\begin{array}{l}\% \text { of AS } \\
\text { attained } \\
\text { with M }\end{array}$ & $\begin{array}{l}\text { of AS } \\
\text { attained } \\
\text { with E }\end{array}$ \\
\hline NZ Māori & 76 & 17 & 24.4 & 43.9 & 21.3 & 10.4 \\
Pasifika & 83 & 18 & 24.3 & 44.4 & 20.9 & 10.4 \\
Asian & 96 & 22 & 13.0 & 33.6 & 29.1 & 24.3 \\
MELAA (Middle & 96 & 22 & 16.7 & 40.0 & 26.8 & 16.5 \\
$\quad$ Eastern/Latin & & & & & & \\
$\quad \begin{array}{l}\text { American/ } \\
\text { African) }\end{array}$ & & & & & & \\
Other & 100 & 24 & 13.3 & 36.2 & 29.4 & 21.2 \\
NZ European/ & 101 & 24 & 14.2 & 37.9 & 28.5 & 19.4 \\
Pākehā & & & & & &
\end{tabular}

The percentages are based on the total number of candidates for whom results are registered and does not include students who did not attempt the standard or were absent from the examination

Table 72015 NCEA Level 1 success indicators broken down by ethnic group using an ethnic proportional weighting approach

\begin{tabular}{lllllll}
\hline Ethnic group & $\begin{array}{l}\text { Mean number of } \\
\text { credits attained in } \\
\text { NCEA Level 1 }\end{array}$ & $\begin{array}{l}\text { Mean number } \\
\text { of AS passed } \\
\text { with A or higher }\end{array}$ & $\begin{array}{l}\text { \% of AS } \\
\text { attained } \\
\text { with N }\end{array}$ & $\begin{array}{l}\text { \% of AS } \\
\text { attained } \\
\text { with A }\end{array}$ & $\begin{array}{l}\text { \% of AS } \\
\text { attained } \\
\text { with M }\end{array}$ & $\begin{array}{l}\% \text { of AS } \\
\text { attained } \\
\text { with E }\end{array}$ \\
\hline NZ Māori & 74 & 17 & 25.0 & 44.2 & 20.7 & 10.0 \\
Pasifika & 86 & 19 & 25.0 & 44.7 & 20.4 & 9.9 \\
Asian & 96 & 23 & 13.2 & 33.8 & 29.0 & 24.0 \\
MELAA (Middle & 96 & 23 & 17.0 & 40.3 & 26.5 & 16.2 \\
$\quad$ Eastern/Latin & & & & & & \\
$\quad \begin{array}{l}\text { American/ } \\
\text { African) }\end{array}$ & & & & & & \\
Other & 100 & 24 & 13.8 & 36.6 & 29.0 & 20.6 \\
NZ European/ & 101 & 24 & 14.5 & 38.1 & 28.3 & 19.1 \\
$\quad$ Pākehā & & & & & \\
\hline
\end{tabular}

The percentages are based on the total number of candidates for whom results are registered and does not include students who did not attempt the standard or were absent from the examination

The analysis of NCEA Level 1 results for the subset of students who nominate more than one ethnic group using the priority ranked method highlights that the NZ European/Pākehā category disappears completely. This is because the NZ European/Pākehā ethnic group is the lowest ranked ethnicity. Multi-ethnic students who nominate NZ European/Pākehā as one of their ethnicities are redistributed to the other groups using this method.

Table 9 shows the ethnic group achievement in NCEA using the weighted mean method. 
Table 8 Ethnic group achievement in NCEA reported using the priority ranked method

\begin{tabular}{lllllll}
\hline Ethnic group & $\mathrm{N}$ & $\begin{array}{l}\text { Ethnic } \\
\text { composition \% of } \\
\text { total }\end{array}$ & $\begin{array}{l}\text { Mean no of achievement } \\
\text { standards attained }\end{array}$ & SD & $\begin{array}{l}\text { Mean no of } \\
\text { credits passed }\end{array}$ & SD \\
\hline Asian & 548 & 7.9 & 26.4 & 8.1 & 109.2 & 31 \\
MELAA & 101 & 1.5 & 24.4 & 9.6 & 101.8 & 36.8 \\
NZ & 0 & 0 & NA & NA & NA & NA \\
$\quad$ European/ & & & & & & 35.2 \\
Pākehā & & & 19.7 & 9.4 & 86.5 & 30.8 \\
NZ Maori & 4821 & 69.4 & 26.2 & 8.4 & 108.7 & 33.9 \\
Other & 553 & 8.0 & 21.9 & 9 & 93.1 & 34.4 \\
Pasifika & 920 & 13.3 & 21.2 & 9.2 & 91.9 & \\
Total & 6943 & 100.0 & & & & \\
\hline
\end{tabular}

The $69.4 \%$ of the multiple ethnicity cohort who were labelled as NZ Māori using the ranked ethnicity method reduced to $33.8 \%$ when the weighted method is used. Correspondingly the NZ European/Pākehā category increased from 0 to $38.4 \%$.

Overall the reported range of differences in achievement between the ethnic groups appears slightly reduced using a weighted mean analysis. The range of the mean number of achievement standards passed is slightly reduced from $26.4-19.7=6.7$ to $25-19.6=5.4$ and the range of the mean number of credits attained is slightly reduced from $109.2-86.50=22.7$ to $104.1-86.5=17.6$.

Tables 8 and 9 show that the achievement of Māori students for both the mean number of achievement standards passed and the mean number of credits attained is the same using the priority ranked approach and the weighted mean approach to analysing the NCEA level 1 results. However the range of the means for both the mean number of credits and the number of standards attained is less using the

Table 9 Ethnic group achievement in NCEA reported using the weighted ethnicity method

\begin{tabular}{lrllrlr}
\hline Ethnic group & $\mathrm{N}$ & $\begin{array}{l}\text { Ethnic composition } \\
\text { \% of total }\end{array}$ & $\begin{array}{l}\text { Mean no of } \\
\text { achievement } \\
\text { standards attained }\end{array}$ & SD & $\begin{array}{l}\text { Mean no of } \\
\text { credits passed }\end{array}$ & SD \\
\hline Asian & 395 & 5.7 & 25 & 8.8 & 104.1 & 33.2 \\
MELAA & 71 & 1.0 & 23.6 & 9.8 & 99.4 & 36.8 \\
NZ European/ & 2666 & 38.4 & 21.7 & 9.5 & 93.3 & 35.1 \\
$\quad$ Pākehā & & & & 9.4 & 86.5 & 35.2 \\
NZ Maori & 2347 & 33.8 & 19.6 & 10.3 & 103.4 & 39.5 \\
Other & 527 & 7.6 & 24.5 & 10.7 & 89.1 & 41.4 \\
Pasifika & 937 & 13.5 & 20.5 & 9.7 & 91.9 & 36.2 \\
Total & 6943 & 100 & 21.2 & & & \\
\hline
\end{tabular}


weighted method making the differences between the NZ Māori group and the other ethnic groups less pronounced.

A $t$ test was used to investigate the difference between the mean number of credits $\left(M_{r}-M_{w}=93.1-89.1=4\right)$ and the mean number of standards attained $\left(M_{r}-M_{w}=21.9-20.5=1.4\right)$ for the Pasifika group. These differences were not statistically significant ( $\mathrm{p} \geq 0.05)$.

\section{Conclusion and Recommendations}

Since there are a multitude of different nationalities, cultures and ethnicities in New Zealand the aggregation of ethnicities to four or five groups does not provide particularly useful data to inform educational planning and goal setting. The differences within these groups can be as pronounced as the differences between the groups.

To enhance the cultural validity of the reporting of national educational outcomes, the study recommends that the current classification groupings be reviewed to better meet the needs of educational decision makers. In particular The MELAA category needs to be reviewed to provide more educationally useful data analysis.

The challenge for educators is to present educational data in a manner that is equitable for people of all ethnicities and which enables the analysis and monitoring of ethnic disparities. In addition our commitment to the principles of the Treaty of Waitangi requires a culturally valid approach to statistically analysing the participation and performance of Maori students in our education system.

The MoE and NZQA use ethnicity priority ranking or a total ethnicity approach to analyse and report on key national educational outcomes for different ethnic groups. Assigning students compulsorily to an ethnic group determined by an imposed algorithmic statistical process is insensitive to the cultural aspirations of our education system and an inappropriate and controversial way of reporting national educational outcomes. The system of priority ranking effectively removes the cultural diversity of the NZ European/Pākehā category by excluding all other ethnicities and can distort the reporting of ethnic group differences for key national outcomes of the education system.

In some instances like the national engagement data on suspensions and expulsions the ethnic priority ranking exacerbates negative outcomes for Maori students which has the effect of unfairly misrepresenting ethnic groups and strengthens the deficit approach to educational planning.

In other instances like the reporting of national achievement data, the ethnic priority ranking ameliorates differential ethnic group reporting. This has the effect of masking and under reporting of trends with a resulting negative impact on the effort to reach national achievement targets. This effect is also observed with the total ethnicity approach used to analyse ethnic comparisons in national school attendance data.

In the current socio-political climate it is time to re-examine the practice of ethnic priority ranking and explore alternative more culturally valid and inclusive 
approaches to statistically analysing ethnic differentials in national educational outcomes.

To enhance the cultural validity of the ethnic reporting of national achievement data for NCEA and provide a fairer reporting of educational outcomes for multiethnic students, the research supports the view that all of the ethnic groups identified by individual students should be taken into account using a weighted proportional representation approach. This is especially important since the educational interventions schools put in place to reach $\mathrm{MoE}$ achievement targets for Maori are targeted at students who meet the current statistical definition and may therefore be unfairly labelled or not receive the appropriate level of educational support. When viewed from a historical perspective this seems to be the next logical step in the evolution of reporting.

The analysis of the national data set for the 2015 Level 1 NCEA cohort shows that the weighted ethnicity approach is a feasible alternative that is statistically sound and practical. It addresses the social concerns about the present approach. A change to this system of reporting would not impact significantly on the reporting of key outcomes and can be adopted without compromising longitudinal time series data or the longitudinal monitoring of progress towards national targets.

The findings of this study show that the way that ethnicity is categorised can have an impact on the reporting of national educational outcomes and may mask, ameliorate or exacerbate effects and trends. Since these data are used by policy makers to identify priorities and monitor and set national targets, it is vitally important that a culturally valid approach is used. Researchers, policy makers and practitioners need to be aware of the impact of labelling. This study has strong implications for other sectors that use the Statistics New Zealand system of ethnic priority ranking like Health and Justice and Social welfare.

Open Access This article is distributed under the terms of the Creative Commons Attribution 4.0 International License (http://creativecommons.org/licenses/by/4.0/), which permits unrestricted use, distribution, and reproduction in any medium, provided you give appropriate credit to the original author(s) and the source, provide a link to the Creative Commons license, and indicate if changes were made.

\section{References}

Aud, S., Fox, M., \& KewalRamani, A. (2010). Status and Trends in the Education of Racial and Ethnic Groups (NCES 2010-2015). U.S. Department of Education, National Center for Education Statistics. Washington, DC: U.S. Government Printing Office.

Australian Bureau of Statistics. (2011). Census Dictionary. Retrieved November 11, 2016 from http:// www.abs.gov.au/ausstats/abs@.nsf/Lookup/2901.0Chapter602011.

Bishop, R., Berryman, M., Cavanagh, T., \& Teddy, L. (2009). Te Kotahitanga: Addressing educational disparities facing Maori students in New Zealand. Teaching and Teacher Education. doi:10.1016/j. tate.2009.01.009.

Cohen, R. (1978). Ethnicity: problem and focus in anthropology. Annual Review of Anthropology, 7, 383-384.

Cormack, D., \& Robson, C. (2010). Ethnicity, national identity and 'New Zealanders': considerations for monitoring Māori health and ethnic inequalities. Wellington: Te Rōpū Rangahau Hauora a Eru Pōmare. 
Khawaja, M., Boddington, B., \& Didham, R. (2000). Growing Ethnic Diversity in New Zealand and its Implications for Measuring Differentials in Fertility and Mortality. Statistics New Zealand.

Kukutai, T. (2004). The problem of defining an ethnic group for public policy: who is Māori and why does it matter? Social Policy Journal of New Zealand, 23, 86-108.

Ministry of Education. (2010). Participation and Attainment of Māori students in National Certificate of Educational Achievement. Retrieved November 9, 2016 from https://www.educationcounts.govt.nz/ statistics/maori-education/maori-in-schooling/participation-and-attainment-of-maori-students-in-nationalcertificate-of-educational-achievement.

Ministry of Education. (2016a). The Māori Education Strategy: Ka Hikitia: Accelerating Success 2013-2017. Retrieved November 27, 2016 from http://www.educationcounts.govt.nz/topics/maori_ education/nga-haeata-matauranga-annual-report-on-maori-education.

Ministry of Education. (2016b). Pasifika Education Plan 2013-2017. Retrieved December 16, 2016 from http://www.education.govt.nz/ministry-of-education/overall-strategies-and-policies/pasifikaeducation-plan-2013-2017/.

Ministry of Education. (2016c). Education Counts: Stand-downs, Suspensions, Exclusions and Expulsions from School. Retrieved November 14, 2016 from http://www.educationcounts.govt.nz/indicators/ main/student-engagement-participation/Stand-downs-suspensions-exclusions-expulsions.

Ministry of Education. (2016d). Education Counts: Students Attending School Regularly. Retrieved November 14, 2016 from http://www.educationcounts.govt.nz/indicators/main/student-engagementparticipation/1935.

Murphy, N. (2003). Joe Lum v. the Attorney General: the politics of exclusion. In M. Ip (Ed.), Unfolding history, evolving identity: The Chinese in New Zealand. Auckland: Auckland University Press.

Nichol, T. (2015). Māori students still struggling with stereotypes and Racism. NewsWire.co.nz, Whitireia, New Zealand. Retrieved November 14, 2016 from http://www.newswire.co.nz/2015/03/ maori-students-still-struggling-with-racism-stereotypes/.

Statistics New Zealand. (2004). Report of the review of the measurement of ethnicity. Wellington: Statistics New Zealand.

Statistics New Zealand. (2009). Final report of a review of the official ethnicity statistical standard 2009. Wellington: Statistics New Zealand.

Statistics New Zealand. (2013). 2013 Census QuickStats about national highlights. Retrieved November 15, 2016 from http://www.stats.govt.nz/Census/2013-census/profile-and-summary-reports/quickstatsabout-national-highlights/cultural-diversity.aspx.

Statistics New Zealand. (2016). Statistical standard for ethnicity. Retrieved November 9, 2016 from http://www.stats.govt.nz/methods/classifications-and-standards/classification-related-stats-standards/ ethnicity.aspx/ethnicity/StatsNZstatistical-standard.pdf.

Taonui, R. (2011). Ngā tuakiri hōu - New Māori identities - New terms for a new world, Te Ara - the Encyclopedia of New Zealand. Retrieved December 5, 2016 from http://www.TeAra.govt.nz/en/ interactive/29826/census-questions.

United Nations. (2007). United Nations declaration on the rights of indigenous peoples. Retrieved November 10, 2016 from https://www.un.org/development/desa/indigenouspeoples/declaration-onthe-rights-of-indigenous-peoples.html. 